\title{
Acute effects of high-dose thyrotropin releasing hormone infusions in Alzheimer's disease
}

\author{
Alan M. Mellow ${ }^{1} *$, Trey Sunderland ${ }^{1}$, Robert M. Cohen ${ }^{2}$, Brian A. Lawlor ${ }^{1}$, James L. Hill ${ }^{1}$, Paul A. Newhouse ${ }^{1 * *}$, \\ Martin R. Cohen ${ }^{3}$, and Dennis L. Murphy ${ }^{1}$ \\ ${ }^{1}$ Unit on Geriatric Psychopharmacology, Laboratory of Clinical Science, National Institute of Mental Health, \\ Bethesda, MD 20892, USA \\ ${ }^{2}$ Section on Clinical Brain Imaging, Laboratory of Cerebral Metabolism, National Institute of Mental Health, \\ Bethesda, MD 20892, USA \\ ${ }^{3}$ Ensor Research Laboratory, William S. Hall Psychiatric Institute, University of South Carolina School of Medicine, \\ Columbia, SC 29028, USA
}

\begin{abstract}
Thyrotropin releasing hormone (TRH) was administered intravenously to ten patients with Alzheimer's Disease (AD) in a high-dose paradigm, thought to maximize central nervous system effects and potentially produce facilitation of cholinergic function, a known property of the neuropeptide. Acute effects of TRH on behavioral, cognitive and physiologic measures were assessed after patients received $0.1 \mathrm{mg} / \mathrm{kg}$ TRH, $0.3 \mathrm{mg} / \mathrm{kg}$ TRH and placebo, the higher TRH dose and placebo being given in a randomized, double-blind fashion. Patients showed statistically significant increases in arousal and improvement in affect, as well as a modest improvement in semantic memory, all after receiving the higher TRH dose. Both TRH doses produced transient rises in systolic blood pressure, with no effect on diastolic blood pressure, heart rate or temperature. This study suggests that high-dose TRH can be safely administered to $\mathrm{AD}$ patients and is neurobehaviorally active; further studies are needed to determine the extent and mechanism of the cognitive and psychobiological properties of this peptide in $A D$ and other neuropsychiatric disorders.
\end{abstract}

Key words: Thyrotropin releasing hormone - Alzheimer's Disease - Neuropeptides

In addition to its role in the regulation of thyroid function, thyrotropin releasing hormone (TRH) has long been recognized as a modulatory neuropeptide, with a broad spectrum of central nervous system (CNS) activity (Griffiths 1985; Horita et al. 1986). Abundant extra-hypothalamic TRH receptors have been demonstrated in both rodent (Pazos et al. 1985) and human brain (Manaker et al. 1986), and while considerable animal data has accumulated concerning the brain effects of TRH, little is known of the central consequences of TRH action in humans. Although TRH interacts with several classical neurotransmitters, the most robust

\footnotetext{
* Current addresses: Department of Psychiatry, University of Michigan Medical Center, Ann Arbor, MI 48109, USA

** Department of Psychiatry, University of Vermont College of Medicine, Burlington, VT 05405, USA

Offprint requests to: A.M. Mellow, Neuroscience Laboratory, University of Michigan, 1103 East Huron, Ann Arbor, MI 48104-1687, USA
}

evidence is for a positive modulatory effect of TRH on the action of acetylcholine (Ach) in the CNS (Breese et al. 1975; Yarbrough 1976; Schmidt 1977; Yarbrough and Singh 1977; Kalivas and Horita 1980; Pirola et al. 1983; Yarbrough 1983). Alzheimers Disease (AD) is a neuropsychiatric disorder characterized clinically by progressive dementia; a prominent neurochemical feature of the illness is a loss of cortical markers for presynaptic Ach and a degeneration of cholinergic pathways; such cholinergic loss appears to correlate with clinical severity of the dementia (Davies and Maloney 1976; Whitehouse et al. 1982; Sims et al. 1983). In addition, TRH levels have been reported to be decreased in the cerebrospinal fluid of dementia patients (Oram et al. 1981), although not in post-mortem brain tissue (Yates et al. 1983). Because of its known positive neuromodulatory effects on cholinergic transmission, we chose to examine, in a pilot fashion, the acute behavioral, cognitive and physiologic effects of TRH in a group of patients with $\mathrm{AD}$ in an effort to explore whether a "neuromodulatory' strategy was feasible in this illness, as has previously been suggested (Yarbrough and Pomara 1985).

TRH has been reported to have antidepressant properties (Kastin et al. 1972; Prange et al. 1972) and to be beneficial in schizophrenia (Wilson et al. 1973a; Inanaga et al. 1978); these results have not been consistently replicated and remain controversial (Davis et al. 1975; van den Burg et al. 1976). A major limitation of previous psychopharmacologic studies with TRH, including one small study with $\mathrm{AD}$ patients (Peabody et al. 1986), has been the use of doses which, although high enough to maximally stimulate pituitary function, are probably too low to gain sufficient CNS access to produce neurobehavioral effects (Nagai et al. 1980; Sunderland et al. 1986). TRH is extremely labile in the circulation (Bassiri and Utiger 1973), owing to active enzymatic degradation (Redding and Schally 1969). Animal studies suggest that the doses required to produce behavioral effects are 10-100 times higher than those which maximally evoke thyroid stimulating hormone (TSH) release (Metcalf 1982). In this pilot study, therefore, we have administered TRH in intravenous doses up to 40 times those given previously in psychopharmacologic and endocrine studies of psychiatric patients, in hopes of achieving sufficient brain levels to observe central effects of TRH. A preliminary version of this work has been previously reported in abstract form (Mellow et al. 1987). 


\section{Methods}

Ten patients (five males, five females; mean age $64.3 \pm$ 2.2 years) were studied while inpatients on the NIMH Unit on Geriatric Psychopharmacology. All patients met DSMIII-R criteria for Primary Degenerative Dementia of the Alzheimer Type (American Psychiatric Association 1987) as well as NINCDS-ADRDA criteria for "probable" Alzheimer's Disease (McKhann et al. 1984). Mean duration of illness was $4.1 \pm 0.5$ years and the mean Global Deterioration Scale (Reisberg et al. 1982) severity index was $4.6 \pm 0.3$, indicating moderate dementia. Patients were without serious medical illness or coexistent psychiatric disorder, and had received no psychoactive drugs for at least 3 weeks prior to the study. Patients underwent 3 separate study days (at least $72 \mathrm{~h}$ apart) as follows: On day 1 , every patient received TRH, $0.1 \mathrm{mg} / \mathrm{kg}$, under single-blind conditions. On days 2 and 3 , patients received TRH, $0.3 \mathrm{mg} / \mathrm{kg}$ or placebo, in a randomized fashion. Both patients and physician-investigator were blind to drug/placebo conditions on days 2 and 3 . The first day of single-blind infusion was included, since the safety of high doses of TRH in this population had not been established; an initial dose of $0.1 \mathrm{mg} / \mathrm{kg}$ was chosen to detect patients who might have unusual sensitivity to the peptide. Every patient completed all 3 days of the protocol.

After an overnight fast, TRH or saline placebo was administered through an inwelling intravenous catheter as a bolus infusion over $1 \mathrm{~min}$. Behavioral measures were made $30 \mathrm{~min}$ prior to drug infusion and 30 and $90 \mathrm{~min}$ after infusion and included: (1) Brief Psychiatric Rating Scale (BPRS; Overall and Gorham 1962), (2) an observer-rated $100 \mathrm{~mm}$ Visual Analog Scale (VAS) for assessment of arousal, affect, motor behavior, orientation and verbal expression, designed to assess potential behavioral effects of cholinergic enhancement (Tariot et al. 1988), and (3) Modified NIMH Self-Rating Scale (van Kammen and Murphy 1975). The cognitive battery was administered along with the behavioral ratings and included: (1) vigilance task (measure of attention) - patients were read a list of 18 words, of which 6 were read once and 6 read twice, and were asked to note any repeated word; (2) category retrieval (measure of semantic or "knowledge" memory) - patients were asked to generate related words over a 90-s period in response to a category stimulus (Bättig and Montague 1969; Tariot et al. 1988); (3) picture recognition task (measure of visual memory) - patients were shown ten simple pictures and, after a distractor task, shown the original pictures interspersed with ten new pictures and asked to identify old and new pictures; (4) Buschke selective reminding task (Buschke 1973) (measure of episodic verbal memory) - this task was modified for use with AD patients by decreasing the test word list from 12 to 6 words (Sunderland et al. 1987). Two patients were unable to complete the cognitive battery due to the severity of their dementia at baseline; cognitive measures are reported for the remaining eight patients. Blood pressure and heart rate were measured at 5-min intervals using an automated vital signs monitor (Critikon Inc., Tampa, FL), and oral temperature was measured at 30 -min intervals.

Data were analyzed with SAS statistical software (Cary, $\mathrm{NC}$ ) by analysis of variance (ANOVA) with repeat measures; Pearson product-moment correlation coefficients were calculated for correlation of behavioral with physio- logic data. Analyses were done without regard to order of drug presentation. Post hoc paired $t$-tests were performed on difference scores when the overall ANOVA showed an interaction (difference scores are reported for clarity of presentation; ANOVAs revealed no significant baseline differences across treatment conditions). Significance was at the $P=0.05$ level. TRH was purchased from Peninsula Laboratories (Belmont, CA) and analyzed for purity with high pressure liquid chromatography by the NIH Pharmaceutical Development Service.

\section{Results}

Physical effects. All patients tolerated the infusions without major adverse reactions. Most experienced transient shivering, urinary urgency and hot and cold cutaneous sensations, which lasted about $5 \mathrm{~min}$, primarily after receiving the higher TRH dose. No patients experienced nausea or vomiting.

Behavioral measures. The results of the behavioral measurements are summarized in Table 1. In the majority of instances, when a significant behavioral effect occurred, it was detected by ratings obtained 30 min after drug infusion. The observer-rated Visual Analog Scales (VAS, Table 1A)

Table 1. Behavioral effects of high-dose TRH infusions in $\mathrm{AD}$ patients $(n=10)$. Patients were rated $30 \mathrm{~min}$ before and 30 and $90 \mathrm{~min}$ after drug/placebo infusions. Each value represents mean $\pm S E M$ for the maximal change from baseline measurement for each treatment condition. $P$ values refer to post hoc paired $t$-tests on difference scores for those conditions showing an interaction on the ANOVA. In the majority of instances, maximum changes were detected by ratings obtained $30 \mathrm{~min}$ after drug infusion.

A

\begin{tabular}{lccc}
\hline & Placebo & TRH (0.1) & TRH $(0.3)$ \\
\hline "Flushing" & $0.3 \pm 1.7$ & $1.9 \pm 2.2$ & $0.0 \pm 2.0$ \\
"Motor Activation" & $5.2 \pm 2.5$ & $3.7 \pm 4.0$ & $9.5 \pm 3.1^{\mathrm{b}}$ \\
"Affect" & $3.3 \pm 4.2$ & $2.1 \pm 5.0$ & $14.3 \pm 3.3^{\mathrm{a}}$ \\
"Arousal" & $1.6 \pm 3.0$ & $0.2 \pm 4.8$ & $13.0 \pm 5.9^{\mathrm{a}}$ \\
"Orientation" & $0.2 \pm 5.5$ & $5.7 \pm 6.7$ & $1.8 \pm 5.1$ \\
"Expression" & $1.3 \pm 2.1$ & $4.2 \pm 2.6$ & $-0.9 \pm 2.5$
\end{tabular}

$\mathbf{B}$

\begin{tabular}{lrrr}
\hline & Placebo & TRH (0.1) & TRH (0.3) \\
\hline "Activation-Euphoria" & $1.8 \pm 1.8$ & $5.0 \pm 2.6$ & $9.8 \pm 4.3^{\circ}$ \\
"Altered Self" & $0.2 \pm 0.6$ & $-1.5 \pm 0.7$ & $0.8 \pm 1.1$ \\
"Anxiety" & $1.5 \pm 3.5$ & $7.2 \pm 5.2$ & $4.0 \pm 1.8$ \\
"Depressed Affect" & $1.0 \pm 2.2$ & $-0.8 \pm 2.8$ & $-0.5 \pm 3.3$ \\
"Dysphoria" & $0.0 \pm 2.5$ & $1.0 \pm 1.4$ & $2.3 \pm 1.6$ \\
"Functional Deficit" & $0.6 \pm 6.7$ & $-3.0 \pm 3.9$ & $5.3 \pm 6.3$ \\
\hline
\end{tabular}

a Significant difference from placebo $(P<0.05)$. b Trend for difference from placebo $(P<0.15){ }^{\mathrm{c}}$ Significant change from baseline $(P<0.02)$

A Effects on Visual Analog Scale (VAS) ratings. Patients were rated by a physician-investigator on six behavioral factors, each measured on a $100 \mathrm{~mm}$ line continuum.

B Effects on NIMH Self-Ratings. Patients provided self-ratings on a 24-item questionaire covering various subjective mental states, rated from 0 (not present) to 10 (present in extreme). Subscale analysis of these data yields six behavioral parameters, each with a maximum score of 100 


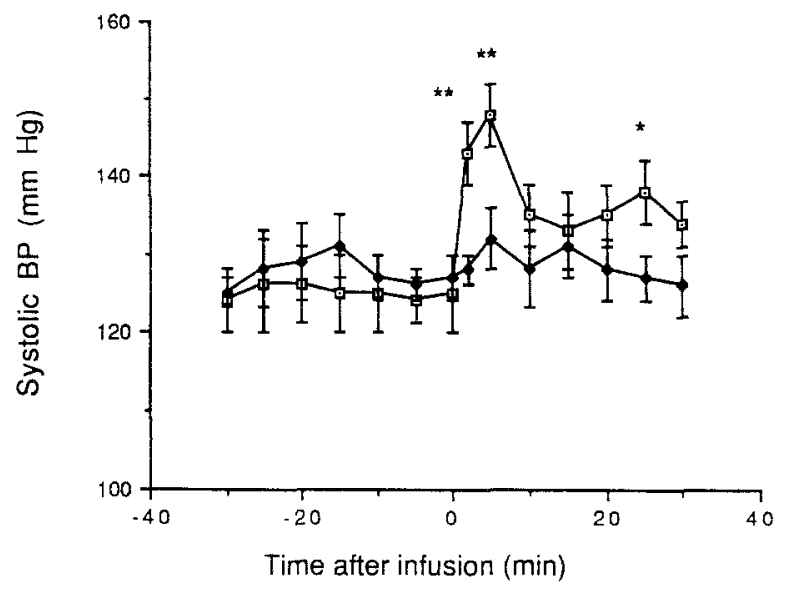

Fig. 1. Effect of high-dose $(0.3 \mathrm{mg} / \mathrm{kg})$ TRH infusion on systolic blood pressure (SBP) in AD patients $(n=9)$. Blood pressure was measured with an automated cuff system (Critikon) at five minute intervals. ${ }^{*} P<0.01,{ }^{*} P<0.05$, different from placebo. A smaller, but significant rise in SBP was seen after infusion of TRH, $0.1 \mathrm{mg} /$ $\mathrm{kg}$ (graph not shown - see text). - $\square \mathrm{TRH}, 0,3 \mathrm{mg} / \mathrm{kg}$; -- placebo

showed a significant drug effect $(P<0.05)$ for an increase in positive affect and an increase in arousal when patients received the higher $(0.3 \mathrm{mg} / \mathrm{kg}) \mathrm{TRH}$ dose. There was also a significant increase in motor activation (compared to baseline) after the higher dose. These objective behavioral changes were also reflected in a small increase in the selfrating score for the "Activation-Euphoria" subscale on the NIMH Self-Rating Scale (Table 1B). Overall BPRS scores did not change significantly with either drug dose; however, a subscale analysis of the BPRS showed a trend increase in the "Mania" score with the $0.3 \mathrm{mg} / \mathrm{kg}$ dose of TRH compared to placebo (data not shown).

Cognitive measures. No effects of TRH infusions were noted on measures of attention (vigilance task), episodic memory (Buschke task) or visual memory (picture recognition task). There was, however, a statistically significant drug-placebo difference in semantic memory as measured by category retrieval. The $0.3 \mathrm{mg} / \mathrm{kg}$ dose of TRH showed a drug-placebo difference of $3.8 \pm 1.2$ words, in the direction of improvement on drug $(P<0.02)$, a $34 \%$ difference in change from baseline.

Physiologic measures. TRH produced significant, early, transient systolic blood pressure (BP) elevations at both doses. The means \pm SEM of the maximum rise over baseline in $\mathrm{mm} \mathrm{Hg}$ were as follows: placebo: $5.1 \pm 2.6$; TRH, $0.1 \mathrm{mg} / \mathrm{kg}: 13.4 \pm 4.2 \quad(P<0.05$ different from placebo $)$; TRH, $0.3 \mathrm{mg} / \mathrm{kg}: 23.4 \pm 3.9(P<0.01$ different from placebo). The BP response to the higher TRH dose is depicted in Fig. 1. There were no significant effects of TRH infusions on diastolic BP, temperature, or heart rate. There were also no significant correlations between peak change in systolic $\mathrm{BP}$ and any behavioral or cognitive measures.

\section{Discussion}

This study represents the first attempt to examine the effects of the neuropeptide thyrotropin releasing hormone in $\mathrm{AD}$ patients, using an acute infusion paradigm with doses we believe to be high enough to directly affect CNS function. TRH produced a small, acute improvement in mood and increase in arousal and motor activity. One drawback of the current study is the "blindedness" of the design, since many of the patients experienced physical side-effects during active drug infusion. However, several patients had little recall of side-effects during subsequent rating, yet still developed increased arousal, so we believe this phenomenon to reflect a true drug effect. Furthermore, the effects are consistent with those seen in animal studies where TRH can increase locomotor activity (Miyamoto and Nagawa 1977; Masserano and King 1981), as well as in human studies, in which TRH, at lower doses, produced a mild euphoric response (Wilson et al. 1973 b, 1980). The mechanisms for these findings are incompletely understood, although it has been suggested that the augmentation of locomotor activity is dopaminergically mediated (Horita et al. 1986) and the effects on arousal may be related to the so-called "analeptic" properties of TRH (Metcalf and Dettmar 1981), with a cholinergic component being prominent (Kalivas and Horita 1980). They are unlikely to be due to stimulation of the thyroid axis, since effects can be seen in hypophysectomized animals (Breese et al. 1975). Moreover, the euphoriant effect of low-dose TRH in humans appears to be negatively correlated with plasma TSH response (Wilson et al. 1973 b, 1980), and high doses of TRH do not appear to further stimulate pituitary TSH release in animals (Metcalf 1982) or humans (Mellow, unpublished observations).

The modest cognitive effects of TRH in this study are difficult to interpret; improvement in word generation may be due only to the arousing effects of the drug or to a selective effect on semantic memory function, since measures of attention were unaffected. This study examined only acute effects of the peptide, and it is possible that with chronic administration, more substantial effects on cognition might be observed. For example, in a recent study, Brambilla et al. (1986), demonstrated some cognitive improvement in chronic schizophrenics given daily, lowdose TRH infusions. Finally, it may be that the neurochemical lesions in AD preclude facilitation of cholinergic function; alternatively, the doses used in the present study may be just at or below the threshold for major cognitive effects. In a recent study from our group (Molchan et al. 1988), TRH, at doses even higher than the present study, partially reversed the impairment in new learning induced by the anticholinergic drug scopolamine in normal controls; under these circumstances, when the underlying cholinergic systems are intact, TRH may have positive modulatory effects on memory.

The systolic blood pressure changes seen after TRH infusions in this study are similar in time course and magnitude to those found by Borowski et al. (1984) after $500 \mu \mathrm{g}$ TRH infusions in a large group of euthyroid patients. A similar rise in blood pressure was also seen by Mitsumoto et al. (1986) during continuous high-dose infusion of TRH to patients with amyotrophic lateral sclerosis. The precise mechanism of the pressor effect of TRH is unknown, although it is thought to involve central stimulation of the sympathetic nervous system (Horita et al. 1986). The lack of correlation of BP changes with behavioral/cognitive changes in this study suggests the possibility of separate mechanisms. It is of interest that we found no significant rise in diastolic BP; in a recent study, the diastolic BP response to TRH in AD patients was significantly blunted 
compared with age-matched controls (T.H. Lampe, personal communication). In light of recent evidence for a cholinergic component to the TRH pressor effect (Okuda et al. 1987), these and our own findings might be a reflection of central cholinergic deficits in $\mathrm{AD}$.

In conclusion, in this pilot study, high-dose intravenous $\mathrm{TRH}$ could be administered safely to $\mathrm{AD}$ patients. The behavioral and physiologic changes seen were similar to those found in earlier studies with much lower doses in normal controls. It remains to be determined whether even higher doses will produce more pronounced or qualitatively different findings, since the doses used in the present study may only be at the threshold for significant central action (Metcalf 1982). Cognitive changes were minimal, but suggested a small, positive effect on semantic memory. Further work is needed with this and other patient populations, as well as with normal controls, to determine the parameters of dosage as well as the extent and mechanisms of the psychobiological actions of TRH in humans. Finally, the present study provides a basis for further investigations into the role of this neuropeptide in the possible pharmacological treatment of the behavioral changes seen in AD.

Acknowledgement. The authors wish to acknowledge the assistance and support of the NIMH 6-D nursing staff during the conduct of this study.

\section{References}

American Psychiatric Association (1987) Diagnostic and statistical manual of mental disorders, 3rd edn. American Psychiatric Association, Washington, DC

Bassiri RM, Utiger RD (1973) Metabolism and excretion of exogenous thyrotropin releasing hormone in humans. J Clin Invest $52: 1616-1619$

Battig W, Montague N (1969) Category norms for verbal items for 56 numerical categories. J Exp Psychol Monogr 80:1-43

Borowski GD, Garofano CD, Rose LI, Levy RA (1984) Blood pressure response to thyrotropin-releasing hormone in euthyroid subjects. J Clin Endocrinol Metab 58:197-200

Brambilla F, Aguglia E, Massironi R, Maggioni M, Grillo W, Castiglioni R, Drago F (1986) Neuropeptide therapies in chronic schizophrenia: TRH and vasopressin administration. Neuropsychobiology 15:114-121

Breese GR, Cott JM, Cooper BR, Prange AJ, Lipton MA, Plotnikoff NP (1975) Effects of thyrotropin-releasing hormone (TRH) on the actions of pentobarbital and other centrally acting drugs. J Pharmacol Exp Ther 193:11-22

Buschke $H$ (1973) Selective reminding for analysis of memory and learning. J Verb Learn Verb Behav 12:543-550

Davies P, Maloney AJF (1976) Selective loss of central cholinergic neurons in Alzheimer's disease. Lancet I : 1403

Davis K, Hollister L, Berger P (1975) Thyrotropin-releasing hormone in schizophrenia. Am J Psychiatry 132:951-953

Griffiths EC (1985) Thyrotrophin-releasing hormone: endocrine and central effects. Psychoneuroendocrinology 10:225-235

Horita A, Carino MA, Lai H (1986) Pharmacology of thyrotropinreleasing hormone. Annu Rev Pharmacol Toxicol 26:311-332

Inanaga K, Nakono T, Nagata T, Tanaka M, Ogawa N (1978) Behavioral effects of protirelin in schizophrenia. Arch Gen Psychiatry $35: 1011-1014$

Kalivas PW, Horita A (1980) Thyrotropin-releasing hormone: neurogenesis of actions in the pentobarbital narcotized rat. J Pharmacol Exp Ther 212:203-210

Kastin AJ, Schalch DS, Ehrensing RH, Anderson MS (1972) Improvement in mental depression with decreased thyrotropin response after administration of thyrotropin-releasing hormone. Lancet II : 740-742
Manaker S, Eichen A, Winokur A, Rhodes CH, Rainbow TC (1986) Autoradiographic localization of thyrotropin releasing hormone receptors in human brain. Neurology 36:641-646

Masserano JM, King C (1981) TRH increases locomotor activity in rats after injections into the hypothalamus. Eur $\mathbf{J}$ Pharmacol $69: 217-219$

McKhann G, Drachman D, Folstein M, Katzman R, Price D, Stadlan EM (1984) Clinical diagnosis of Alzheimer's Disease: report of the NINCDS-ADRDA Work Group. Neurology 34:939-944

Mellow AM, Sunderland T, Cohen RM, Lawlor BA, Newhouse PA, Gross M, Weingartner H, Murphy DL (1987) Acute physiologic, behavioral and cognitive effects of high-dose TRH infusions in Alzheimers patients. Soc Biol Psychiatry Abstr, p 392

Metcalf G (1982) Regulatory peptides as a source of new drugs - the clinical prospects for analogues of TRH which are resistant to metabolic degradation. Brain Res Rev 4:389-408

Metcalf G, Dettmar PW (1981) Is thyrotropin releasing hormone an endogenous ergotropic substance in the brain? Lancet I: $586-589$

Mitsumoto M, Salgada ED, Negroski D, Hanson MR, Salanga VD, Wilber JF, Wilbourn AJ, Breuer AC, Leatherman J (1986) Amyotrophic lateral sclerosis: Effects of acute intravenous and chronic subcutaneous administration of thyrotropin releasing hormone in controlled trials. Neurology 36:152-159

Miyamoto M, Nagawa Y (1977) Mesolimbic involvement in the locomotor stimulant action of thyrotropin-releasing hormone (TRH) in rats. Eur J Pharmacol 44:143-153

Molchan SE, Mellow AM, Sunderland T, Lawlor BA, Efron LA, Cohen MR, Cohen RM (1988) Attentuation by thyrotropin releasing hormone of scopolamine-induced memory impairment in normal volunteers. Soc Biol Psychiatry Abstr, p 171

Nagai Y, Shigeharu Y, Nagawa Y, Hirooka Y, Nihei N (1980) Blood level and brain distribution of thyrotropin-releasing hormone (TRH) determined by radioimmunoassay after intravenous administration in rats. J Pharm Dyn 3:500-506

Okuda C, Mizobe T, Miyazaki M (1987) The involvement of central cholinergic mechanisms in cardiovascular responses to intracerebroventricular and intravenous administration of thyrotropin-releasing hormone. Life Sci 40:1293-1299

Oram J, Edwardson J, Millard P (1981) Investigation of cerebrospinal fluid neuropeptides in idiopathic senile dementia. Gerontology 27:216-223

Overall JE, Gorham DR (1962) The brief psychiatric rating scale. Psychol Rep 10:799-812

Pazos A, Cortés R, Palacios JM (1985) Thyrotropin-releasing hormone receptor binding sites: autoradiographic distribution in the rat and guinea pig brain. J Neurochem 45:1448-1463

Peabody CA, DeBlois TE, Tinklenberg JR (1986) Thyrotropin releasing hormone and Alzheimer's disease. Am J Psychiatry $143: 262-263$

Pirola CJ, Balda MS, Finkielman S, Nahmod VE (1983) Thyrotropin-releasing hormone increases the number of muscarinic receptors in the lateral septal area of the rat brain. Brain Res 273:387-391

Prange AJ, Wilson IC, Lara PP, Alltop LB, Breese GR (1972) Effects of thyrotropin-releasing hormone in depression. Lancet II :999-1002

Redding TW, Schally AV (1969) Studies on the inactivation of thyrotropin releasing hormone (TRH). Proc Soc Exp Biol $131: 415-419$

Reisberg B, Ferris SH, Delean MJ, Crook T (1982) The global deterioration scale for assessment of primary degenerative dementia. Am J Psychiatry 139:1136-1139

Schmidt DE (1977) Effects of thyrotropine releasing hormone (TRH) on pentobarbital-induced decrease in cholinergic neuronal activity. Commun Psychopharm 1:469-473

Sims NR, Bowen DM, Allen SJ, Smith CCT, Neary D, Thomas DJ, Davison AN (1983) Presynaptic cholinergic dysfunction in patients with dementia. J Neurochem 40:503-509

Sunderland T, Mellow AM, Gross M, Cohen RM, Tariot PN, 
Newhouse PA, Murphy DL (1986) Thyrotropin-releasing hormone and dementia. Am J Psychiatry 143:1318

Sunderland T, Tariot PN, Cohen RM, Weingartner H, Mueller EA, Murphy DL (1987) Anticholinergic sensitivity in patients with dementia of the Alzheimer's type and age-matched controls: a dose response study. Arch Gen Psychiatry 44:418-426

Tariot PN, Cohen RM, Welkowitz JA, Sunderland T, Newhouse PA, Murphy DL, Weingartner H (1988) Multiple dose arecoline infusions in Alzheimer's disease. Arch Gen Psychiatry 45:901905

van den Burg W, van Pragg HM, Bos ERH, Piers DA, van Zenten AK, Doorenbos H (1976) TRH by slow, continuous infusion: an antidepressant? Psychol Med 6:393-397

van Kammen DP, Murphy DL (1975) Attenuation of the euphoriant and activating effects of $d$ - and $l$-amphetamine by lithium carbonate treatment. Psychopharmacologia 44:215-224

Whitehouse PJ, Price DL, Struble RG, Clark AW, Coyle JT, Delong MR (1982) Alzheimer's disease and senile dementia: Loss of neurons in the basal forebrain. Science 215:1237-1239

Wilson IC, Lara PP, Prange AJ (1973a) Thyrotrophin-releasing hormone in schizophrenia. Lancet II: 43-44

Wilson IC, Prange AJ, Lara PP, Alltop LB, Stikeleather RA, Lipton MA (1973 b) THR (lopremone); psychobiological responses of normal women: I. Subjective experience. Arch Gen Psychiatry $29: 15-21$
Wilson IC, Prange AJ, Loosen PT (1980) Psychological and thyroid-stimulating hormone changes after thyrotropin-releasing hormone in normal women: antagonism by pretreatment with thyroid hormones. Psychiatry Res $2: 211-222$

Yarbrough GG (1976) TRH potentiates excitatory actions of acetylcholine on cerebral cortical neurones. Nature 263:523-524

Yarbrough GG (1983) Thyrotropin releasing hormone and CNS cholinergic neurons. Life Sci 3:111-118

Yarbrough GG, Pomara N (1985) The therapeutic potential of thyrotropin releasing hormone in Alzheimer's disease. Prog Neuropsychopharmacol Biol Psychiatry 9:285-289

Yarbrough GG, Singh DK (1977) Intravenous thyrotropin releasing hormone (TRH) enhances the excitatory actions of acetylcholine (Ach) on rat cortical neurons. Experientia 34:390

Yates CM, Harmar AJ, Rosie R, Sherward J, Sanchez deLevy G, Simpson J, Maloney AFJ, Gordon A, Fink G (1983) Thyrotropin releasing hormone, luteinizing hormone-releasing hormone and substance $P$ immunoreactivity in post-mortem brain from cases of Alzheimer-type dementia and Down's syndrome. Brain Res 258:45-52

Received September 6, 1988 / Final version February 7, 1989 